\title{
LOSING AND FINDING REALITY IN THE VIRTUAL WORLD: MEDIA REPRESENTATION OF SAUDI CULTURE - THE CASE OF THE MINISTRY OF CULTURE
}

\author{
ROAA IBRAHIM ASSAS \\ Graphic design department, Jeddah university, Saudi Arabia
}

\begin{abstract}
This study investigates Saudi character in general and its Islamic nature in the virtual world in particular. Big changes are underway in the country, evident in entertainment, cultural authorities, art, tourism and more. This paper takes the Ministry of Culture website in Saudi Arabia as a case study, a Ministry that was created only recently on $2^{\text {nd }}$ June 2018 under the leadership of His Highness Prince Badr bin Abdullah bin Farhan Al Saud. This study found that the Ministry of Culture online interface design is simple and uses a mixture of warm and cold colours in a white space, which improves the usability. The content in general is easy to read. Moreover, the Ministry utilizes social media platforms, i.e. Instagram and Twitter, for advancing its agenda and propaganda. As a result, the design of the website is similar to the design of social networks popular in Saudi Arabia. This study shows how media is a great tool in shaping Saudi culture. It is also one of the aspects that plays a great role in changing the stereotype of Saudi Arabia, abandoning the image of a country that was dependent on oil, is culturally conservative and plagued with terrorism. In conclusion, Saudi Arabia is a rich and colorful culture emerging with a new image and the Ministry of Culture is significantly changing the old stereotypes in line with its vision of 2030. It was not as clear before as it is now as, unlike never before, this Ministry is now the mirror of the Saudi culture for the world to see.

Keywords: branding, web design, media, user experience, Saudi Arabia, culture, stereotype, Ministry of Saudi culture, interface design.
\end{abstract}

\section{INTRODUCTION}

\subsection{Saudi Arabian culture}

Saudi Arabia is the largest country on the Arabian Peninsula and located in the south-west part of Asia. It is referred to as "the land of the two Holy Mosques" with Makkah and Madinah based in Saudi Arabia. It was unified in 1932 under King Abdul Aziz Al Saud and it is a Monarchy governed by Islamic Share'aa law, which operates in accordance with Sunni Islam.

Culture is a deeply rooted set of beliefs and traditions and can be contrasted with the concept of "civilization", which entails modernity, urbanization and industrialization [1]. Saudi Arabia is a rich culture both Arabic and Islamic. Over numerous years society indorsed enormous modernity while without losing its heritage and values. However, they adopted a modern revamp of the heritage in order to adapt with the present times. According to Klepeis, when people talk about Saudi Arabia, they still imagine that life there is worn and behind [2]. Online and offline platforms are different as they regenerate each other, they are separate arenas of self-display to the world [3].

\subsection{The Ministry of Culture}

The Ministry of Culture is a new sector that was created in 2018 under the leadership of Prince Badr bin Abdullah bin Farhan Al Saud. This Ministry was formally launched in 2019 
when they broadcast the cultural vision for the Kingdom of Saudi Arabia. This Ministry aims to shed light on all aspects of Saudi society such as art, festivals, architecture and design, museums, archaeology, heritage and literature. Their vision is to create a vibrant, ambitious society and a flourishing economy. The main purpose of this Ministry is to show the multi-cultural identity of the Saudi Arabia.

\subsection{The website design of the Ministry of Culture}

Although it can be seen that the website is a beta version, content analysis was conducted to study the design of the website as a descriptive qualitative approach. The methodology the researcher used was by Luna-Nevarez and Hyman [4] who analyzed Destination marketing organization (DMO). They used six factors to evaluate, which are: primary focus, navigation and interactivity, visual and presentation style, textual information, use of advertising, and use of social media and travel aids. In this research all of these factors have been used and is shown in Table 1.

Table 1: Website characteristics.

\begin{tabular}{ll}
\hline Measured variable & Value \\
\hline Primary focus: & \\
Predominantly informative/cultural & Yes \\
Predominantly commercial/transactional & Yes \\
Informative-commercial & \\
& \\
\hline Visual and presentation style: & \\
& \\
Page size & \\
Small (1-2 screens) & No \\
Large (3 or more screens) & Yes \\
Page layout & Yes \\
Unbalanced & Yes \\
Number of images & More than 5 images \\
Few images & \\
Many images & \\
& \\
Presence of: & \\
The Ministry brand & \\
Animated images (slide show) & Yes \\
Animated buttons (links) & Yes \\
Pop-up images & No \\
Audio & Yes \\
Video & No \\
& Yes \\
\hline
\end{tabular}


Table 1: Continued.

\begin{tabular}{ll}
\hline Measured variable & Value \\
\hline Navigation and interactivity & \\
Presence of: & \\
Site map & No \\
Search tool & No \\
Languages other than local & Two languages \\
& \\
Level of interactivity & No \\
Small (main menu with $0-5$ links) & Yes \\
Medium (main menu with 6-10 links) & No \\
High (main menu with more than 10 links) &
\end{tabular}

\begin{tabular}{ll}
\hline Textual information & \\
$\begin{array}{l}\text { Presence of: } \\
\text { Homepage title } \\
\text { Text length } \\
\text { Few words or Many words }\end{array}$ & Yes \\
\hline Advertising & Many \\
$\begin{array}{l}\text { Number of banner ads (Adn) } \\
\text { Animated ad (Aad) }\end{array}$ & \\
$\begin{array}{l}\text { Ad product type (Adp) } \\
\text { Main ad size (Ads) }\end{array}$ & No \\
$\begin{array}{l}\text { Presence of animated ads } \\
\text { Product type }\end{array}$ & Small ( $>1 / 8$ of screen) \\
$\begin{array}{l}\text { Non-cultural related } \\
\text { Cultural related }\end{array}$ & Large $(<1 / 8$ of screen) \\
Size & No \\
Small (r1/8th screen) Large (41/8th screen) & \\
\end{tabular}

Social media and cultural aids

Presence of:

Social media $\quad$ Yes

City map $\quad$ Yes

Weather information No

Calendar of events $\quad$ Yes

Booking service $\quad$ Yes 


\section{CONTENT METHODOLOGY ANALYSIS}

\subsection{Primary focus}

The first evaluation factor that was used by Luna-Nevarez and Hyman (2012) to analyse the website design is the primary focus. This factor means what kind of information the website contains and whether it is commercial or not. Usually, informative websites cover cultural aspects, places to visit, local news, and weather. Sometimes they give users the opportunity to interact with different commercial companies in order to buy tickets for events and book courses or hotels. The Ministry of Culture mainly gives information about the Ministry and its functions since it is a new addition in the country. On the "Home page", it identifies itself as the identity of Saudi Arabia in big bold text in the middle of the page as the first thing the user's eyes catch. When scrolling down the website there is a message to the users which gives them an impression of being welcome and involving them. It also gives a brief description about the Ministry's vision and mission. Then, news related to the Ministry is provided which can be clicked on for more information. At the bottom their location, contact details, and social networks such as Instagram, Twitter, YouTube, Facebook and Linkedin are listed. A button labelled "Career" is visible next to this for job seekers who may wish to work at the Ministry.

The About page offers two choices: "About the Ministry" and a message from the Minister. When clicking on "About the Ministry" more information about the Ministry opens with its vision and mission. By clicking "the message from $\mathrm{HH}$ " you will be directed to a letter from the Minister to the user.

The roadmap shows the four key principles driven by a strategic approach which are promoting, preserving, supporting and leading with a brief description of every principle. The vision and guidance of the Ministry of Culture and its three central objectives are also presented. This page shows how the Ministry focused on 16 sub-sectors illustrated simply and each under its icon. Moreover, there is a grouped list of cultural initiatives combining art, music, children's programs, festivals and more. Finally, the user can download the vision file for more information.

Selecting the "Media Centre" would take the user to the news section where some broadcasts titles related to the Ministry are displayed. Under this, there is "multimedia and publications". Furthermore, the user will find more of any of the above when clicking the "more" button. On the calendar page the user will find a calendar where different events organized by the Ministry of Culture are listed in order of date. When clicking on an event the date, time and location appears. For more information, Google maps is provided under each event with methods of communication such as Twitter, WhatsApp, Facebook, email and a printing icon to print the page.

On the public engagement page there are many titles of events and contests which are funded by the Ministry of Culture for people to participate in. For example, there is the Year of Arabic Calligraphy 2020 event which gives people the opportunity to show the beauty and history of Arabic calligraphy. Users from both the private and public sectors can participate. Another example is the Industrial Heritage competition which includes challenges that aim to engage and motivate all segments of society to highlight the industrial history of the Kingdom.

Finally, the FAQ page contains the frequently asked questions related to the Ministry. The user can find seven questions listed and when clicking on each question the answer will roll down from it. 


\subsection{Visual and presentation style}

The next factors analyzed are page size, layout, number of images and the presence of the brand.

\subsubsection{Page size}

The size of the Ministry of Culture's page is $44.16 \mathrm{~KB}$, which is 45224 Bytes.

\subsubsection{Page layout}

This classification identifies the design principles such as its composition and balance. The page layout of the Ministry is asymmetric. In design, unsystematic balance tends to be more interesting to draw attention [5]. Moreover, asymmetrical designs can evoke feelings of movement. This is why so many sports brands use asymmetrical layouts and asymmetry in individual elements (such as the logo) [6].

The header of the site is white, and the logo of the Ministry is shown on the left in the English version and with the Arabic version on the right. The header comes down when scrolling the website.

An image of the Minister Prince Badr bin Abdullah Al Saud is shown in black and white on the left in English and on the right in Arabic. Colorful patterns from the logo slides to the image to emphasize the image.

In terms of image usage, at the top of the "About" page on the website there is a slider of Video Footage that provides images of the country of Saudi Arabia. It shows the flag moving in the wind, different historical landmarks, deserts and mountains taken from the sky. In the middle of the images in a dark grey color text "Explore the Ministry of Culture" and under it the phrase "our culture our identity" with the 16 sub-sections bellow the images. These icons also slide and can be chosen according to the user's interest. On every page at the top there are images that represent the culture of Saudi Arabia with a colour effect on every image from the logo. This is reflected in a study from 2015 that found that social network users prefer providing the web page with images of landmarks and children rather than themselves [7].

The body of the website is mainly white and the footer, located on the bottom, is in dark blue and the texts are in white which allowing a great contrast and makes it clear to read.

\subsubsection{The number of images}

There are more than five images that represent the culture from craft to landscape. They are mainly at the top of each page and also in the news section.

\subsubsection{Presence or absence of the Ministry brand (i.e. logo), animated images, animated buttons (i.e. menu items), pop-up images, audio, and video.}

The website does not contain any pop-up images, but users could find the logo of the Ministry in the header. The header moves down while scrolling down the website. Also, the Ministry is using the same colours used in the logo as the theme colours of their brand. There is only one video that represents the culture of Saudi Arabia on the website. There are no animations, only geometric parts of the logo moving vertically and stopping around the Prince's image which could symbolize him as the brain of the Ministry.

\subsection{Navigation and interactivity}

The concept of "interactivity" depends on two-way communication between the users and associations which can be from one person to another or from one person to a group of people 
or an organization to another [8]. Users could interact with the Ministry by contacting them for a number of reasons. First of all, the website gives users the opportunity to show their talent by sending their CVs and what they are gifted in. It also gives the impression of encouragement to help people progress and find a good career while highlighting how the Ministry believes in the power of the Saudi people. Secondly, users could interact with the Ministry in the Public engagement section. On this page there are courses and events users could click on to register or participate. However, the website lacks a sense of community even though its UX is positive but building this cultural community would give a stronger impression [9]. In the case of the Ministry site it is supposed to be a web-based community network for users who are interested in any aspect of the website to connect with other people who have great influence and can help them [10]. While scrolling around the website there can be seen a simplicity of using and navigating the site without unnecessary clicking of buttons. This was suggested by a study that social networks made computer networks and sites social [11].

\subsection{Textual information}

More than half of the website contains text-based information in a simple and brief way. It does not bother the viewer and overwhelm them with a lot of unnecessary information that could make a negative UX. The use of words is easy to understand and common. Also, there are titles at the top of every paragraph which gives the reader an idea about what information they will find. The most common words used on this website is: passion, culture, involvement, art, events, history, youth, initiative and activities. They are all positive words that give the reader hope that life is going to be ok. A research conducted about the effect of information literacy on trust in government websites stated the more information the website presents the more users trust the website "this is mediated by one's perceived information overload (negatively) and perceived usefulness (positively)" [12]. Moreover, this is similar to previous research regarding usability of Hungarian governmental websites that suggested to avoid using too small font sizes because small text makes reading difficult for visually impaired people [13].

\subsection{Advertising}

The website contains advertisements related to the Ministry such as programs, events and jobs. For example, the Year of Arabic Calligraphy 2020 platform is an initiative that encourages calligraphers to participate to highlight the importance and beauty of this ancient art. These adverts come under the news section for the viewers. The website does not use the word advertisement but uses the "news or media" phrase since it gives a sense of realistic matter and this might be because the word "news" excites the viewer to read and attract them to find a way to show their passion. The way that the Ministry publishes this news by narratively reporting current information could be of interest to the audience in an equilibrium and well-versed approach in order to promote events [14]. Advertisements are usually paid for by clients but in this case these entities are sponsored by the Ministry that does not get paid.

\subsection{Social media}

The website contains most of the popular social networks such as Instagram, Twitter, YouTube, Facebook and Linkedin. These social networks are active and verified and can be seen under all the sector under the Ministry such as visit Saudi Arabia that got $76.8 \mathrm{~K}$ 
followers on Instagram as it contains professional photography of beautiful scenery in Saudi Arabia. Another example is the Ministry Instagram which has $267 \mathrm{~K}$ followers and on Twitter they have $579.7 \mathrm{~K}$ followers. This gives the impression that the Ministry is engaging and communicating with the public using more than one platform. They are not taking social media for granted. They also use multimedia to highlight what the Ministry's mission, vision, objectives and sections are to establish a sense of trust with their audience and keep them informed of their latest news and events [15]. It is important to highlight the amount of social network usage by Saudis as according to global media the most used media platforms in SA is YouTube with 24.71 million users, after it is Facebook and Instagram and the least of them is Twitter with 5.8 million users [16].

\section{DISCUSSION}

The Internet acts as a vast network, allowing people to start and maintain relationships. Manuel Castells (2001) argues that the Internet has enabled and sustained what he describes as "networked individualism" in which individuals, families and organizations try to position themselves in ways that help them to meet their aims and objectives (127) [17].

A successful website should give a positive user experience (UX) in order to make the viewer come back and forth to it [18]. From my point of view, the website of the Ministry of Saudi UX is satisfying in the sense that it has visual content that is not using a dramatic decorative art that could distract the user from its main content and messages. According to Zheng (2018) users would neglect a website in 15 seconds if they got distracted or lost interest in it [19]. Even though the Ministry is an umbrella organization of 27 organizations in 16 sectors within the UNESCO framework covering various areas such as arts and crafts, music, typography and more [20], it shows all of this without the feeling of overloading the user. It is really simple and elegant as I think it represents the culture of its country dynamically. The website would also give the feeling to the Saudi user that it is a guide that turns ideas and dreams into reality as it opens doors to ambitious artists, writers, talents to show what they have in order to express their feelings and emotions to the public which can be as a starting point for their career. It encourages Saudis to be world leaders in different aspects. This kind of content and promotional aspects seem to be the best approach to generate awareness and maintain viewers' interest [21].

The website of the Ministry focuses more on the most important information (text-based content) in an enthusiastic but simple way. On the other hand, animated images of slideshows display the attraction of the country such as Al Oula which is an ancient land near Madina city that used to be a silent destination that Saudis only see as the place of torment to the Prophet Saleh's people. The Ministry illustrates this land from the positive side showing the beauty of its sunrise and its important archaeological terminus for tourists throughout the world. Many resorts have been made on a lot of residential places, conference venues, restaurants and relaxing areas where people could do hiking and yoga [22]. Also, pictures of different ancient cities such as Rejal Almaa and Al Diriyah that were restructured and reformed show the cities' beauty and history to be tourist destinations as well [23]. It also contains additional endearing images of local cultural events and destination logos with an elegant layout that communicates well with the end user [21]. Moreover, the homepage of the website has a balanced design that is influenced by social media such as Facebook and LinkedIn that contain one screen with several excellent images.

The website does not use a great deal of multimedia such as videos and audio stream that pop up. As some studies such as Bittner and Zondervan (2015) [24] suggested, pop-up images and windows can be effective. However, other studies such as Gehrke and Turban (1999) and Maria et al. (2020) thought that successful website design using a lot of multimedia 
popups can be disturbing and distasteful, as they confuse the user from the key content of a website and therefore should be prevented [25], [26]. Some researchers think pop-ups need to be smart and relevant to the website in order to be successful [27].

The main menus on the website page contain no more than seven links that is simple to the point with a pleasing design on a white background. These links take the user to different pages on the same website with limited text. Moreover, facilities such as language versions Arabic, which is the main language in Saudi Arabia, and English, which is the second most common language in the country and is globally recognized by foreign visitors and researchers. Also, site maps of different locations and main events simplify the effort of information seeking which reduce the exploration period of specific aspects and events which make positive UX [19].

This analysis found that the website's branding highlights the many cultural sectors under the Ministry. It is for users who are looking for primary helpful content, as it offers simple visuals that could guide them straight to their interests in order to get more detail about what they want to participate in. The branding of the Ministry is consistent with a clear goal for the website. The logo combines both hot and cold colours which can describe the comfort and warmth of this culture. It contains 13 coloured lines, and the logo reflects its diversity in thirteen regions in Saudi Arabia [28]. Some aspects of it shown while browsing the website without being distracted with colours details and the amount and features. As the lines and aspects from the logo are animated to guide the eye to specific important information, the Ministry offers such as their vision and services. Also, the website shows the importance of the vision 2030 that supports the Ministry by showing the logo of it on the bottom of each page.

The links of all social networks for the Ministry give the impression that the Ministry knows about the use of these networks in order to reach their target audience. The audience are people who are interested in many aspects of the Saudi culture such as events, arts and knowledge. It seeks to demonstrate the beautiful and peaceful characteristics of Saudi Arabia. However, this research suggests the addition of a chat button at the end of the home page to communicate more with visitors and to help guide them more if they need.

\section{CONCLUSION}

The inclusion of this research shows that the website is a platform that promotes all cultural practices related to art, literature, museums, tourism, heritage and more. The Ministry website design is different from old governmental websites as it moved from a complicated user experience to a really simple yet ethically appealing design. The focus of the website is to guide the users of the important content and information. There is a balance of content by using images where needed and texts without popup ads and multimedia use that could be distracting.

According to the outcomes of this research the website is functional as the most important aim of it is to let the user gather as much information as possible in a minimum time and energy which shown in the number of clicks required to move from page to another. Furthermore, the number of screens is not distracting as it is minimal and modest and can give the user the feeling of ease by facilitating content personalization to specific target groups who are interested in any aspects that the Ministry support.

With the increasing use of the internet amongst people of all ages the website is a reasonable tool to promote the new vision of Saudi Arabia and its culture. The Ministry realized how much Saudis rely on web-based technologies as they specified all new features and social media accounts under their supervision on the website for more information as evidenced. 
To sum up, the research suggests that the website could give a positive reaction to the Ministry's practices. This is by the analysis of the amount of visual and text-based information. The website is a mirror of the Saudi cultural practices and sites that many people and researchers were not aware of, especially those who were distracted by media stereotyping of the country and the people there. In support of this research, a quantitative methodology can be used in order to explore more information preferred by the guests' wishes and preferences. The Ministry of culture website helps promote the new Saudi Arabia and the real image of a peaceful and beautiful Saudi Arabia rather than a land that is not known for its developments and growth. Most importantly, it highlighted the passionate and peaceful side of the Saudi culture which is overlooked by the negative narrative from the media. Finding this image of the country that was lost virtually is the focus of the Ministry with all of its sectors under it to prove and show the true identity of Saudi Arabia.

\section{REFERENCES}

[1] Pollock M., Third Culture Kids - The Experience of Growing Up Among Worlds, Intercultural Press: Yarmouth, 2001.

[2] Klepeis A., Understanding Saudi Arabia Today, Mitchell Lane Publishers: USA, 2014.

[3] Hamidaddin A., Tweeted Heresies: Saudi Islam in Transformation, Oxford University Press: USA, 2019.

[4] Luna-Nevarez, C. \& Hyman, M., Common practices in destination website design. Journal of Destination Marketing \& Management, 1(1-2), pp. 94-106, 2012.

[5] Bradley S., Design Principles: Compositional, Symmetrical And Asymmetrical Balance - Smashing Magazine. Smashing Magazine, 2015.

www.smashingmagazine.com/2015/06/design-principles-compositional-balancesymmetry-asymmetry/. Accessed on: 6 Mar. 2020.

[6] Babich, N., Symmetry vs. asymmetry in layout design. Shopify, 2018. www.shopify.com/partners/blog/asymmetrical-design. Accessed on: 12 Mar. 2020.

[7] Guta, H. \& Karolak, M., Veiling and blogging: Social media as sites of identity negotiation and expression among Saudi Women. Journal of International Women's Studies, 16(2), pp. 115-127, 2015.

[8] Yeon, H., Choi, Y. \& Kiousis, S., Interactive communication features on nonprofit organizations' webpages for the practice of excellence in public relations. Journal of Website Promotion, 1(4), pp. 61-83, 2007.

[9] Bacon, J., Art of Community: Building the New Age of Participation, 2nd ed., O'Reilly Media: Sebastopol, 2012.

[10] Carroll, J., The Neighborhood in the Internet. 1st ed., Routledge: London, 2014.

[11] Chesher, C., How computer networks became social. Second International Handbook of Internet Research, eds J. Hunsinger, M. Allen \& L. Klastrup, Springer: Dordrecht, 2020.

[12] Lee, T., Lee, B., Lee-Geiller, S., The effects of information literacy on trust in government websites: Evidence from an online experiment. International Journal of Information Management, 52, 102098, 2020.

[13] Heckl, I. \& Csontos, B., Accessibility, usability, and security evaluation of Hungarian government websites, 2020. https://link.springer.com/article/10.1007\%2Fs10209020-00716-9. Accessed on: 6 Apr. 2020.

[14] Struck, K., Student awareness of ads vs. news called "bleak", 2016. www.voanews.com/student-union/student-awareness-ads-vs-news-called-bleak. Accessed on: 7 Apr. 2020. 
[15] Barnhart, B., Social media and government: how to keep citizens engaged, 2020. https://sproutsocial.com/insights/social-media-and-government/. Accessed on: 17 Mar. 2020.

[16] Saudi Arabia Social Media Statistics 2019 (Infographics), 2020. www.globalmediainsight.com/blog/saudi-arabia-social-media-statistics/. Accessed on: 1 Apr. 2020.

[17] Castells, M., The Internet Galaxy, 1st ed., Oxford University Press: Oxford, 2004.

[18] Gangadharan, P., The importance of user experience design, 2019. https://uxplanet.org/the-importance-of-user-experience-design-988faf6ddca2. Accessed on: 4 Apr. 2020.

[19] Zheng, D., The 15 second rule: 3 reasons why users leave a website, 2018. www.crazyegg.com/blog/why-users-leave-a-website/. Accessed on: 1 Mar. 2020.

[20] Kharif, B. \& Habtor, A., Saudi Culture Minister to Asharq Al-Awsat: We want a modern cultural institution that fits all, Asharq AL-awsat, 2019. https://aawsat.com/english/home/article/1654156/saudi-culture-minister-asharq-alawsat-we-want-modern-cultural-institution-fits. Accessed on: 2 Apr. 2020.

[21] Nguyen, L., Website Design and Development, Bachelor of Engineering, information and communications technology. Turku University of Applied Sciences, 2020.

[22] Arab News, Architect Jean Nouvel talks about design for resort among Al-Ula's rocks, 2019. https://www.arabnews.com/node/1450511/saudi-arabia.

[23] Arabian Business, Saudi Arabia's Diriyah to be the "Beverly Hills" of Riyadh, 2019. https://www.arabianbusiness.com/travel-hospitality/421161-saudi-arabias-diriyah-tobe-the-beverly-hills-of-riyadh-says-ceo.

[24] Bittner, J. \& Zondervan, R., Motivating and achievement-eliciting pop-ups in online environments: A user experience perspective. Computers in Human Behavior, 50, pp. 449-455, 2015.

[25] Gehrke, D. \& Turban, E., Determinants of successful website design: Relative importance and recommendations for effectiveness. The 32nd Annual Hawaii International Conference on Systems Sciences, Hawaii: IEEE, p. 8, 1999.

DOI: 10.1109/HICSS.1999.772943. Accessed on: 2 Feb. 2020.

[26] Willermark, S., Islind, A., Appelgren, T. \& Taavo, M., The polite pop-up: An experimental study of pop-up design characteristics and user experience. 53rd Hawaii International Conference on System Sciences, Maui: HICSS, p. 4208, 2020 p. 4208. https://scholarspace.manoa.hawaii.edu/bitstream/10125/64256/0415.pdf. Accessed on: 31 Feb. 2020.

[27] Ratner, B., Should marketers use pop-up forms? A comprehensive analysis. Blog.hubspot.com, 2016. https://blog.hubspot.com/marketing/pop-up-forms-analysis. Accessed on: 8 Mar. 2020.

[28] Almohanna, A., What do the colors indicate in the new "culture" slogan?, Albalad news, 2019. https://web.archive.org/web/20190330101035/https://albalad.news/ Ksa/1139750/إلى-.ماذا_تشير -الألوان-في_شعار _الثقافة_الجديد_Accessed on: 20 May 2020. 